\title{
O uso do onde no texto acadêmico $^{1}$
}

\author{
Janice Helena Chaves Marinho \\ Universidade Federal de Minas Gerais
}

\section{Abstract}

This paper presents a partial analysis of the use of the item onde (where) in academic written texts produced by university students. These texts tend to present several cohesive mechanisms which are responsible for their realability. In general, the author constructs a coherent and cohesive discourse in order to lead his/her reader to the desired meaning. Nevertheless, sometimes he/she fails in using cohesive mechanisms, and that leads to a local incoherence, according to Charolles (1988). One example is the use of onde in written texts. In these texts, several passages were found in which this word was used without reference to places, i.e. not according to what is prescribed by traditional Portuguese grammar. It seems that this use of onde points to a different function, an enlargement of its field of action. 


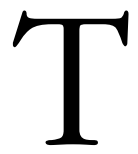

extos acadêmicos, em sua maioria argumentativos formais, produzidos por alunos e professores universitários, tendem a legibilidade. Em geral o autor se empenha em construir um discurso coerente e coeso, que possa levar o leitor a produzir o sentido desejado durante o processamento textual. No entanto, algumas vezes seu objetivo parece não ser alcançado devido a problemas que se devem ao emprego de elementos coesivos - marcadores importantes no estabelecimento da coesão textual.

Um desses problemas recorrentes é o uso do item onde. Gramáticas do português padrão recomendam que ele seja empregado apenas com referência a lugar, estando seu antecedente expresso ou latente. No entanto, observa-se que ele tem sido diferentemente empregado. No presente trabalho, pretendo apresentar uma análise parcial do item onde no texto escrito atuando sem referência a lugar em que e sem um referente, explícito ou latente, o que parece apontar para uma ampliação no seu campo de atuação.

\section{A COERÊNCIA E A COESÃO TEXTUAIS}

O texto não é um amontoado de palavras, nem uma soma ou agrupamento de frases isoladas, desconexas, mas uma seqüência de frases com relações entre si, que forma um "todo unificado". Tais relações, segundo os estudiosos da lingüística textual, se estabelecem pela coerência, responsável pela unidade de sentido do texto, e pela coesão, responsável por sua unidade formal.

A coerência e a coesão são assim dois fatores responsáveis pela textualidade e estão intimamente relacionadas. O simples emprego de 
mecanismos coesivos pode não ser suficiente para a formação de um texto com uma unidade significativa, mas os elementos lingüísticos da coesão costumam dar-lhe maior legibilidade. O sentido do texto depende da interação entre texto, autor e leitor, que, procurando compreendê-lo, deverá ter habilidade para interpretar elementos lingüísticos de coesão, ou seja, recursos utilizados pelo autor para que se estabeleça a coerência. A coesão, então, tem um importante papel no texto, na medida em que os elementos lingüísticos de superfície é que contribuem para o estabelecimento da coerência.

Koch e Travaglia (1993), estabelecendo uma relação entre tipos de texto e coerência, mencionam que, para eles, diferentes tipos de textos apresentariam diferentes graus de coesão e diferentes elementos coesivos. Assim, há textos, como os científicos, didáticos ou expositivos, por exemplo, que parecem tender a apresentar mais elementos coesivos, em que se explicitam os tipos de relações estabelecidas entre os elementos lingüísticos que os compõem. Ou seja, há textos em que o autor faz a opção por explicitar as relações que deseja expressar de modo a conduzir o leitor a uma possibilidade de articulação das proposições, a uma interpretação.

Trabalhando com textos acadêmicos produzidos por alunos e professores universitários, pude verificar que tal afirmação é verdadeira. Nos textos acadêmicos, em sua maioria argumentativos formais, empregam-se recursos coesivos que explicitam as relações textuais subjacentes. Em textos desse tipo, o autor se empenha em construir um discurso coerente e coeso de tal modo que possa levar o leitor a produzir o sentido desejado. Mas, algumas vezes, seu objetivo não é alcançado devido ao emprego problemático de elementos coesivos.

Koch (1987a) assinala que o uso inadequado dos conectores interfrásticos ${ }^{2}$ constitui um dos maiores problemas na produção e recepção de textos, e defende que o estudo dos diversos tipos de conectores interfrásticos, que vise à explicitação e/ou ao reconhecimento das relações textuais marcadas por tais elementos, pode trazer contribuições para a resolução de problemas relacionados à dificuldade de leitura e de produção de textos. 
O emprego inadequado - em que se desobedece à norma do português padrão - de elementos coesivos pode levar a dificuldades na leitura, uma vez que interfere no estabelecimento de inferências bem como na formulação de previsões, processos que fazem parte da compreensão da linguagem. Podemos observar, no exemplo (1) ${ }^{3}$ abaixo, que o uso do pronome anafórico seu acarreta dificuldades para o leitor, já que o pronome poderia estar se referindo a professores, Lingua Portuguesa ou a diferentes escolas.

(1) As perguntas abaixo foram respondidas por diversos professores que lecionam Língua Portuguesa em diferentes escolas, durante um levantamento feito para se verificar seu ensino e eficiência.

O leitor precisa, então, de um maior esforço para interpretar a passagem em (1); tem de possuir outros conhecimentos que o irão orientar na escolha correta do referente ou tem ainda de procurar, em casos como o de (2), o referente a partir de alguma informação posterior do texto.

(2) Com uma frase, uma pergunta bem feita, a pessoa pode até manipular a interpretação da outra e conduzi-la à resposta que quer ouvir. Ela pode ter muitos significados dependendo do contexto onde ela se encaixa, da situação e como foi colocada.

O estudo da coesão textual, bem como o de seus mecanismos, tendo em vista o papel que desempenham na articulação do texto, tornase, então, importante para a análise de passagens como essas aqui exemplificadas.

Sabe-se que a coesão se refere aos meios lingüísticos pelos quais se consegue a textura, ou seja, o que distingue o texto do não-texto. Ela é, pois, um dos componentes da textualidade. Podemos entender a coesão textual como a organização do texto, como o que estabelece as relações de significado existentes dentro do texto, as quais envolvem os elementos lingüísticos que o compõem. A coesão, assim, promove uma relação semântica entre elementos do texto; ela é explicitamente assinalada através de marcas lingüísticas de superfície, ou seja, de mecanismos formais da língua (marcas para o leitor/ouvinte). 
A coesão constrói-se através: de mecanismos gramaticais, que podem ser, por exemplo, os pronomes anafóricos, os artigos, a elipse, os conectores, a concordância, a correlação entre os tempos verbais; de mecanismos lexicais, que podem ser a reiteração, a substituição e a associação de itens lexicais; e ainda através da ordenação de palavras, de constituintes ou de sentenças nos enunciados produzidos.

É importante ressaltar o papel da ordenação dos enunciados no texto na construção da coesão - além do emprego dos mecanismos gramaticais coesivos ou da retomada de itens lexicais - uma vez que esse recurso é que estabelece a coesão em muitos textos. A ordem em que seus enunciados se apresentam é também elemento da materialidade lingüistica do texto a partir da qual o receptor será capaz de calcular relações de sentido.

Van Dijk (1996) afirma que "um discurso não é apenas um conjunto de seqüências, mas uma seqüência ordenada com condicionamentos convencionais sobre as ordenações possíveis". A ordem das palavras e a ordem das sentenças, assim como o uso de conectivos, advérbios sentenciais, pronomes ou tempos verbais, meios que "costumam ser subsumidos sob o conceito de coesão", são algumas das condições do discurso coerente.

A coesão textual, então, se manifesta explicitamente no texto, através de marcas utilizadas pelo autor a fim de possibilitar a seu interlocutor a produção de sentidos que ocorre nas situações de interação. O uso de operadores e conectivos lógicos tem um importante papel na estrutura do texto e por isso tem sido pesquisado pelos estudiosos da organização textual-interativa, que consideram a língua como "fundamentalmente um instrumento de interação social" (Basilio, 1993: 10). Têm sido desenvolvidos trabalhos em que se estudam e se avaliam formas gramaticais como "agora", "então" (consideradas articuladores discursivos) (Risso, 1993, 1996), "mas" (Rodrigues, 1995), os conectores da disjunção (Oliveira, 1995), os modalizadores (Koch, 1987, 1992), os conectores interfrásticos (Koch, 1987a), etc., visando-se à reflexão sobre o estatuto semântico dessas formas, bem como sobre suas propriedades textuais no estabelecimento da coesão. 


\section{O ITEM ONDE}

Partindo desses estudos sobre a coerência e a coesão textuais, e da constatação de que, em textos acadêmicos (argumentativos formais), encontram-se muitas ocorrências nas quais o emprego de mecanismos coesivos contribui para a formação de períodos considerados mal estruturados, já que resultam muitas vezes em incoerências locais (nas palavras de Charolles), procurei desenvolver, neste trabalho, uma análise de um conector interfrástico cujo emprego em textos produzidos por alunos de Graduação, matriculados em disciplinas oferecidas na Faculdade de Letras da UFMG, tem chamado a atenção. Trata-se do item onde.

Esse item é considerado pelas gramáticas do português padrão como advérbio de lugar - já que "indica o lugar em que se situa a ação verbal"- e ainda como pronome relativo (ou advérbio relativo) - que equivale a em que. Recomenda-se que seja empregado apenas com referência a lugar, estando seu antecedente expresso ou latente. No entanto, tenho observado que ele tem sido diferentemente empregado, nos textos acadêmicos pesquisados. Encontrei nesses textos diversos trechos em que o onde não está empregado de acordo com o que prescrevem as gramáticas. Em alguns desses trechos, diria que o uso desse mecanismo coesivo pode ser inclusive apontado como o responsável pelo comprometimento da legibilidade textual, uma vez que ele não possui um referente expresso ou possui um referente não facilmente identificável no texto.

Entre os trechos selecionados, pude perceber o onde atuando como advérbio relativo - elemento anafórico, ou seja, que recupera outro elemento numa sentença -, porém retomando um termo da sentença que o precede sem referência a lugar em que. Na tentativa de investigar sua atuação nesses casos, sou levada a pensar que ele está empregado ora no lugar de em que, ora no lugar de quando, como se exemplifica em (3), (4) e (5):

(3) MC é uma estilista formada em arquitetura e administração de empresas que apresentou sua primeira coleção onde une audácia e sobriedade. 
(4) O verso em Whitman, é feito de enumerações e paralelismos. Whitman inovou na poesia numa época onde tudo o mais já tinha mudado.

(5) A quarta ideologia surge no século XX, onde tem-se uma Universidade pluralista e massificada, com objetivo principal sendo o bem social.

Nesses casos, a sua substituição por um desses itens solucionaria o problema relacionado à não-obediência aos padrões estabelecidos pelas gramáticas.

(3') MC é uma estilista formada em arquitetura e administração de empresas que apresentou sua primeira coleção em que/na qualune audácia e sobriedade.

(4') O verso em Whitman, é feito de enumerações e paralelismos. Whitman inovou na poesia numa época em que tudo o mais já tinha mudado.

(5) A quarta ideologia surge no século XX, quando tem-se uma Universidade pluralista e massificada, com objetivo principal sendo o bem social.

Encontrei também exemplos, como os apresentados abaixo, em que interpreto que o onde está atuando como um conector o qual, além de item anafórico, responsável pela retomada de um referente, estabelece uma relação de explicação/justificação, ou relações de proporcionalidade e de mediação entre as proposições.

(6) A saúde no Brasil está deficitária, onde o governo não apóia os profissionais da área de saúde.

(7) A mesa seria o termômetro da familia onde dependendo da comida ou das atitudes das pessoas ela seria um ponto de união ou discórdia familiar. 
(8) A intertextualidade foi outro critério adotado, onde se pudesse observar em que medida o conhecimento ou não de outros textos interferiria na leitura.

Nesse trechos, podemos interpretar que o onde, na condição de item remissivo, retoma não um elemento mas a idéia expressa na sentença que o precede e, ao mesmo tempo, na condição de conector, relaciona-a com a informação da sentença que se lhe segue, estabelecendo entre as sentenças dos enunciados relações semânticas e/ou pragmáticas.

Percebi, ainda, em outros trechos, o onde atuando sem um referente, explícito ou latente, ou com um referente ambíguo, ou seja, que não é facilmente identificável no texto, e por isso ocasiona ao leitor/ receptor uma dificuldade na leitura ou compreensão do texto. Nestes exemplos a substituição do onde por outro item ou por alguma expressão (locução conjuntiva ou locução adverbial, por exemplo) não tornaria estas passagens mais bem articuladas:

(9) Geralmente são três os entrevistados onde cada entrevista é separada pelo tempo comercial e ao final do programa há quase sempre uma apresentação musical.

(10) Gama Cury reconhece que estes verbos tem predicação incompleta, se completa com um adjunto adverbial, isto é que faz o papel de complemento, onde deveriam ser chamados de transitivos, mas ele não vai contra a nomenclatura tradicional e os classifica como intransitivo, isto é incoerente.

(11) Qualquer comunicação é feita mediante regras naturais interior dos falantes onde as regras cultas são dispensáveis.

(12) Outro ponto importante é a oportunidade do público participar do programa seja através de fax ou do diálogo dirêto; oportunidade criada pela produção e pelo próprio Jô Soares. Além disso cabe ressaltar a banda ou melhor o quinteto presente no show, onde além de tocar é presente em comentários, e alguns deles são os mais esdrúxulos, realizados em momentos do programa. 
Em (9), podemos perceber que o onde não está sintaticamente integrado à sentença a que pertence, tanto que a sua exclusão não prejudicaria a frase numa perspectiva estritamente sintática, o que parece apontar para o fato de que ele está atuando não como advérbio relativo, mas como articulador, que estabelece uma relação coesiva entre proposições. Em (10) e (11), arriscaria dizer que ele sequer possui um referente expresso ou latente. Em (12), podemos interpretar que ele, na sua condição de conector, estaria relacionando segmentos do texto e, na sua condição de forma remissiva, estaria referindo-se tanto a quinteto quanto a show, causando, assim, uma ambigüidade.

O uso do onde então, como podemos verificar através desses exemplos, parece apontar para uma ampliação no seu campo de atuação. Em casos como esses exemplificados neste trabalho, o onde parece atuar no plano textual - como um conectivo textual, importante no estabelecimento da coesão - e não somente no plano frástico, uma vez que ele, em diversos enunciados, não está funcionando apenas como elemento de delimitação ou restrição, o qual restringe a extensão de um termo (que faz referência a lugar ou não) que pertence à outra sentença, função exercida pelo pronome relativo, mas atua numa estrutura mais ampla, como elemento que faz o encadeamento dos enunciados, e estabelece relações textuais/discursivas entre eles.

Essa atuação do item onde, observada em textos escritos, é também encontrada em textos orais, como exemplifico abaixo ${ }^{4}$ :

(13) A indústria brasileira, especificamente a mineira, atingiu determinado estágio onde, sem dúvida nenhuma, podemos ser considerados atores importantes no cenário do mercado mundial industrial.

(14) Temos, portanto, um triângulo que já não diria mais desacoplado, mas bastante maduro, onde o próprio Governo, hoje, consolidou mecanismos, como a Lei no 8.661, que é a chamada "pesquisa cooperativa", onde nenhum dos lados, ainda, explorou positivamente: nós, porque não nos organizamos para mostrarmos o que temos a fazer; as empresas, na realidade, também perdidas no 
processo, sem condições, inclusive, de fazer seu PDTI, que é o Plano de Desenvolvimento Tecnológico Integrado, que deve ser gerado via um documento, mas que, em sua maioria, não o têm.

(15) O trabalhador vai ganhar um salário mínimo? E ele é que vai sustentar a aposentadoria dos professores, onde algumas são cortadas em função do teto. E quem vai pagar? Então, digo: temos que pensar um conjunto de problemas.

Nos exemplos (13) a (15), podemos perceber que o onde está funcionando na organização e no seqüenciamento do discurso e não, conforme a descrição das gramáticas do português padrão, apenas relacionando duas orações, representando um item já referido na oração anterior.

Considerar esse uso do onde como erro, ou seja, "aquilo que foge à variedade que foi eleita como exemplo de boa linguagem" (Possenti, 1996), é uma abordagem normativa, reducionista, que só focaliza o produto, o enunciado, e não o processo de sua produção.

A constatação desse fenômeno nas duas manifestações lingüísticas - na fala e na escrita - conduz à hipótese de que o onde está em processo de gramaticalização - entendido como "o caminho percorrido por uma palavra, ao longo do qual ela muda de categoria sintática, recebe propriedades funcionais na oração, sofre alterações semânticas, morfológicas e fonológicas, e inclusive desaparece, como conseqüência de uma cristalização extrema" (Castilho, 1998) - uma vez que vem desempenhando outras funções além da de advérbio de lugar e da de advérbio relativo. Como pudemos ver através dos trechos aqui exemplificados, ele tem também funcionado como um encadeador discursivo, "responsável pelo encadeamento de enunciados, dando-lhes uma orientação discursiva e estruturando-os em textos" (Koch, 1987a: 89).

A análise do comportamento de itens que atuam na organização discursiva "constitui um campo extraordinariamente fértil para a investigação de fenômenos da estruturação textual-interativa e, portanto, para o tratamento de questões gramaticais que transcendem o âmbito da frase" (Risso, 1996: 447). 


\section{NOTAS}

${ }^{1}$ Este trabalho foi apresentado em 02/09/98 no V Congresso Brasileiro de Lingüística Aplicada, realizado na UFRGS.

${ }^{2}$ Conectores interfrásticos são palavras ou expressões responsáveis pela concatenação de segmentos do texto e pela criação de relações entre eles.

${ }^{3}$ Os exemplos apresentados neste trabalho foram copiados de trabalhos produzidos por alunos de Graduação na FALE/UFMG exatamente como foram escritos.

${ }^{4}$ Esses trechos foram extraídos da transcrição de debates realizados no Congresso Universitário/UFMG, em novembro de 1995.

\section{REFERÊNCIAS BIBLIOGRÁFICAS}

BASÍlIO, Margarida. As abordagens e o objeto de estudo no Projeto Gramática do Português Falado. In: CASTILHO, Ataliba T.(Org.). Gramática do Português Falado. Vol III: As abordagens. Campinas: UNICAMP/FAPESP, 1993.

BASTOS, Lúcia Kopschitz. Coesão e coerência em narrativas escolares. Campinas: Unicamp, 1985.

CHAROLLES, Michel. Introdução aos problemas da coerência dos textos (abordagem teórica e estudo das práticas pedagógicas). O Texto: leitura e escrita. (Org. e revisão técnica da tradução: Charlotte Galves, Eni P. Orlandi, Paulo Otoni). Campinas: Pontes, 1988.

CASTILHO, Ataliba T. de. A lingua falada no ensino de português. São Paulo: Contexto, 1998.

COSTA VAL, Maria da Graça. Redação e Textualidade. São Paulo: Martins Fontes, 1991.

FÁVERO, Leonor Lopes. Coesão e coerência textuais. São Paulo: Ática, 1991.

HALLIDAY, M.A.K. \& HASAN, R. Cobesion in English. London: Longman, 1976.

KOCH, Ingedore G. Villaça, TRAVAGLIA, Luis Carlos. Texto e coerência. 3. ed. São Paulo: Cortez, 1993.

KOCH, Ingedore G. Villaça. A coesão textual. São Paulo: Contexto, 1989. . A inter-ação pela linguagem. São Paulo: Contexto, 1992.

. Linguagem e argumentação.2. ed. São Paulo: Cortez, 1987.

Dificuldades na leitura/produção de textos: Conectores interfrásticos. In.KIRST, Marta, CLEMENTE, Ivo (Orgs.). Lingüística aplicada ao ensino de Português. Porto Alegre: Mercado Aberto, 1987a . 
OLIVEIRA, Hélio F. Os conectores da disjunção. Cadernos de Estudos Lingüisticos. Campinas, UNICAMP, n. 28, jan./jun. 1995.

POSSENTI, Sírio. Por que (não) ensinar gramática na escola. Campinas: ALB/ Mercado de Letras, 1996.

RISSO, Mercedes S. "Agora... o que eu acho é o seguinte": um aspecto da articulação do discurso no português culto falado. In: CASTILHO, Ataliba T. (Org.). Gramática do Português Falado. Vol III: As Abordagens. Campinas: UNICAMP/ FAPESP, 1993.

O Articulador discursivo "então". In: CASTILHO, Ataliba T. \& BASÍLIO, Margarida. (Org. ${ }^{s}$ ). Gramática do Português Falado. Vol IV: Estudos descritivos. Campinas: UNICAMP/FAPESP, 1996.

RODRIGUES, Andréa. Os níveis da atuação do Mas no discurso. Cadernos de Estudos Lingüísticos. Campinas, UNICAMP, n. 28, jan./jun. 1995.

VAN DIJK, Teun. Cognição, discurso e interação. São Paulo: Contexto, 1996. 